\title{
Preprocessing structured clinical data for predictive modeling and decision support
}

\section{A roadmap to tackle the challenges}

José Carlos Ferrão ${ }^{1,2}$; Mónica Duarte Oliveira²; Filipe Janela'; Henrique M. G. Martins ${ }^{3}$

${ }^{1}$ Siemens Healthcare, Rua Irmãos Siemens 1, 2720-093 Amadora, Portugal;

${ }^{2}$ CEG-IST, Centre for Management Studies of Instituto Superior Técnico, Universidade de Lisboa, Av. Rovisco Pais 1, 1049-001 Lisbon, Portugal;

${ }^{3}$ Centre for Research and Creativity in Informatics, Hospital Prof. Doutor Fernando Fonseca, IC-19 Venteira, 2720-276 Amadora, Portugal

In the original article by JC Ferrão et al.: „Preprocessing structured clinical data for predictive modeling and decision support - a roadmap to tackle the challenges", - Table 5 was missing and is presented here.

Appl Cin Inf 2017; 8: 122-123

http://dx.doi.org/10.4338/ACl-2016-03-SOA-0035e published: February 1, 2017

Citation: Erratum to: Ferrão JC, Oliveira MD, Janela F, Martins HMG. Preprocessing structured clinical data for predictive modeling and decision support - a roadmap to tackle the challenges. Appl Clin Inform 2017; 8: 122-123

http://dx.doi.org/10.4338/ACI-2016-03-SOA-0035e 
Table 5 Key usability and acceptability features of structured EHR data (summarizing information from [79, 80]).

\begin{tabular}{|l|l|}
\hline Feature & Description \\
\hline Efficient search mechanism & $\begin{array}{l}\text { Make effective use of search terms, allowing users to search concepts by } \\
\text { different terms and synonyms, while considering variations in acronyms } \\
\text { and special characters }\end{array}$ \\
\hline Relevant search results & Only display search results with relevance to a specific context \\
\hline Logical ordering of terms & $\begin{array}{l}\text { Display terms and search results in a meaningful order (e.g. alphabetically } \\
\text { and/or grouped according to relevant categories) }\end{array}$ \\
\hline Concept lookup enhancement & $\begin{array}{l}\text { Include intelligent functionalities to facilitate concept lookup such as in- } \\
\text { stant search boxes, efficient navigation panes and selective term filtering }\end{array}$ \\
\hline $\begin{array}{l}\text { Group concepts into appropriate } \\
\text { categories }\end{array}$ & $\begin{array}{l}\text { Group concepts into meaningful categories, recognized by users to facili- } \\
\text { tate guidance }\end{array}$ \\
\hline Preferred and clear designations & $\begin{array}{l}\text { Make use of unambiguous and clear designations with which health pro- } \\
\text { fessionals are familiar }\end{array}$ \\
\hline Clear synonyms and abbreviations & $\begin{array}{l}\text { Make use of appropriate synonyms and only include clear and unambigu- } \\
\text { ous acronyms recognized by most or all users }\end{array}$ \\
\hline Exhaustive but relevant concepts & $\begin{array}{l}\text { Provide exhaustive selection of terms for users to choose how to best con- } \\
\text { vey a given concept; include only relevant concepts in order to minimize } \\
\text { overload of information }\end{array}$ \\
\hline
\end{tabular}

